\title{
Surrogate Leadership Model for Digital Organizational Systems
}

http://doi.org/10.21272/bel.4(4).140-146.2020

Olena Skrynnyk, ORCID: https://orcid.org/0000-0001-8300-6616

Postgraduate Student, Technology manager, Modis, Stuttgart, Germany

\begin{abstract}
The increase of investigations regarding digital systems for the social structure mapping leads to dynamizing previously rigidly recorded processes or deliberately ignored ones. Such processes include, among others, matters with a social context, which have been difficult to describe in mathematical terms. This investigation is an integral part of explanatory research on the digital representation of an organization. The main purpose of the study is to investigate the literary sources and approaches to find the determinants of a general surrogate model, to identify the required parameters and their mathematical contents as well, as to design a surrogate model construct capable of application to different digital organizational systems, independent of the dominant behavioural and decision-making pattern of the leadership unit. The relevance of this scientific problem decision is that recently, an increasingly vast number of research investigations on the digitization of anthropological systems is being done. The modeling of the leadership surrogate model is a part of our research on the digitization of organizational systems. Investigation of the topic is carried out in the following logical sequence: analysis of scientific publications on the researched subject and model creation. This part consists of successive steps: abstraction of a real system of management units and the delimitation of the indicated topics, definition of constraints for further simplification of the surrogate model, model construction, establishment of model-describing formalism and obtaining the exact surrogate model based on the dataset. Since our surrogate model has a general character, the last step was described only indicatively. Nevertheless, we consider this to be a tremendous potential extension for the following investigations on different scenarios. The research results can be useful for other scientists searching for research on the mathematical representations of the leadership model, the surrogate model for the leadership unit, and practitioners who intend to implement the leadership model in the digital organization system. The additional parameters can complement the created surrogate model; respectively the considered parameters can be calculated or measured by other methods.
\end{abstract}

Keywords: Digital Organizational Systems, Leadership Model, Surrogate Model, Mathematical Model.

JEL Classification: C690, M120.

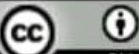

Cite as: Skrynnyk, O. (2020). Surrogate Leadership Model for Digital Organizational Systems. Business Ethics and Leadership, 4(4), 140-146. http://doi.org/10.21272/bel.4(4).140-146.2020.

(C) The Author, 2020. This article is published with open access at Sumy State University.

\section{Introduction}

As the degree of digitalization increases, the company, and its environment change, increasing the complexity of work tasks. Reducing complexity and mastering change are the main tasks of management and leadership. There are numerous classifications which consider leadership from different perspectives: behavioural, situational, integrative, functional, agile, neurobehavioral, Vroom-Yetton-Yago normative leadership model and consider various concepts: charismatic leadership, transformative leadership, attributive leadership, postindustrial leadership concept and holacracy (Tannenbaum \& Schmidt, 1958), (Hersey \& Blanchard, 1988), (Adair \& Adair, 1988), (Kouzes, \& Posner, 2012). Regardless of the classification feature, the measurable characteristics remain the same. The parameters must be related through particular mathematical operations to digitize the relationships in the processes. For this purpose, we have studied numerous publications and selected the necessary mathematical models. These can be implemented with particular adaptation in developed software solutions for organization and management systems. Most of these models do not distinguish between management and leadership and focus on the key differentiators. In our study framework, we form the leadership model, based on tasks and competencies required by jobs, from selected determinants. The surrogate models are applied to reproduce the real behaviour of a system and its components. It accounts for a certain degree of abstraction that results from dynamics that are still unknown or difficult to model. 
Surrogate models for digital leadership are used in high abstraction environments, such as idealizations and approximations, where assumptions and restrictions have to be applied.

\section{Literature Review}

We have explored scientific literature databases Scopus and Web of Science to find the approaches to surrogate organizational leadership models. Neither in the databases nor on the web, we found the appropriate hits. Furthermore, it was decided to create the own surrogate model with selected parameters and functions. For this purpose, the new search iterations were started. The literature review revealed that many researchers have already studied the topic of mathematical representation of leadership models. These models have different degrees of complexity and goals. We want to emphasize the following models particularly:

Acharya provides a mathematical model that essentially describes the structure of the leaders' work styles relative to their subordinate units and respective attributes and is based on contingency theory. This model focuses on the overall pattern of organizational leadership and the interrelationships among units. Leadership determinants are not considered (Acharya, 2010).

$>$ The leadership model based on Multivariate Analysis and Data Envelopment Analysis is designed for mapping the knowledge of a leadership unit to achieve the set business goals (Mejia et al., 2009).

> The leadership model developed by Moradinasab et al. utilizing fuzzy logic with data from Research Institute Petroleum Industry (RIPI) personnel characteristics provides the most appropriate leadership style for the situation and required leadership characteristics (Moradinasab et al., 2016).

Azhmukhamedov \& Protalinskiy have conducted empirical studies on motivation effectiveness and employee performance and validated the theoretical models based on the research findings. In our study, we refer to the findings of these investigations (Azhmukhamedov \& Protalinskiy, 2015).

\section{Methodology and Research Methods}

Our study consisted of the literature review on the investigated purpose and the preformulating of the general surrogate model with selected parameters. Building a surrogate model consists of successive steps: the idealization of the real system and making the approximations and corresponding assumptions. Then follows the definition of the corresponding substitute model, based on appropriate basic equations and principles. A computer can use this model to represent specific scenarios according to the real system dynamics. The definition of the surrogate model consists in making assumptions (with predefined abstraction level and constraints), formulating the data model, and elaboration of formalism.

\section{Results}

The previous classifications subdivide leadership models into sets of specific combinations of these parameters. We have analyzed scientific publications and case studies and have concluded that, on the one hand, current scientific findings reveal that in the era of digitalization, new competencies and leadership styles are required of managers. On the other hand, despite digitalization progress, many companies continue to follow conventional leadership models. Therefore, we consider it reasonable not to the strict frameworks of management models and regard them only as prefabricated fixed-parameter combinations, but as an agile, adaptable construct. According to these principles and gained findings, the general leadership surrogate model can be represented as follows:

Abstraction level. The abstraction level is characterized by simplification of the real system and limitation to the fundamental interrelations or selected scenarios. A leadership model is determined by repeatedly applied working, behavioural, decision-making and control patterns and can be perceived as a combination of characteristics and parameters. Each situation is indicated by specific characteristics expressed at different intensities. Depending on the specific situation, parameters may vary to a certain value or may be completely omitted. By variation of parameters, the real behaviour of the system is expressed. In our leadership model, we do not differentiate between management and leadership functions, since in many cases (small companies, lowest management levels, etc.) these are executed by the leadership unit. Such functions complement each other and comprise leadership, coordination, motivation, organization, initiation, anticipation, vision building, realization, creation, structuring, forward movement, parameter setting, treatment etc. We have formed the knowledge of leadership features gained from the literature research into four facets of leadership:

"Employees" (relates to the subordinates, the directive, the team and all related dimensions, which are related to the guidance, motivation, inspiration, organization, coordination, etc. of employees). 
$>$ "Company" (includes all dimensions of leadership, associated with company guidelines or organizational demands. Since these are often closely related to other facets, we mainly assigned the parameters to corresponding other facets).

$>$ "Working performance" (all work-related dimensions of a leading unit: from the content and quantity context of the tasks to the own and performance of the subordinate units).

$>$ "Decision" (includes all dimensions around the distribution of different amounts of decisions to the subordinate units, as well as share of responsibility assumed).

Leadership behaviour is one of the general determinants of the "Employee" facet. Due to different contexts, this is subdivided into behaviour towards subordinates (employees) and general behaviour. In the first case, it is primarily focused on instruments of the corporate communication style, rewards and punishments, way to regulate conflicts, etc. The general behaviour reflects the reaction of the person to the event. We do not consider this dimension in the described model context but would like to refer to the related study (Skrynnyk \& Vasilyeva, 2020). The "Company" facet is best characterized by centrally set expectations of all kinds (goals, objectives, values, job requirements, etc.). The determinants belonging to the facet "Working performance" refer to these expectations, and the way of their fulfilment.

Constraints. In this step, the constraints are determined to delimit the described case and thus reduce the complexity of the model. Since our model is a general one, the constraints are defined correspondingly in a general manner. In our study, we impose the following constraints:

$>$ Single or multiple persons can execute leadership unit due to increasing importance of plural leadership.

> Power at the formal and informal levels constitutes a precondition for leadership models. We consider only formal power in the creation of our surrogate model.

$>$ Leadership is merely a role with predefined goals and no patterns defined by us.

$>$ The concrete leader uses the same behavioural, decision-making and control patterns over time (in the same situations).

$>$ There are no external influences on the leader.

$>$ The personal characteristics are not shown separately in the described model; therefore, they are considered constant.

$>$ The predefined goal is to increase the company's performance.

$>$ When considering such parameters as effectiveness of motivation, we restrict the parameter as a single factor influencing the performance. The degree of the employee's psychological readiness for work performance $\left(f_{\text {PSRed }}\right)$ is also seen as constant.

$>$ An employee's performance depends on his/her loyalty, level of competence, the conformity degree of his/her psychological and physical states with the working conditions and the psychological climate in the anthropological system of subordinate units. Since in our study we consider the average values of all units subordinated to the leading one, we assume that the employees' competence levels, and their physical and psychological states remain at the constant normal level (all subordinated units have the working ability).

Model. Figure 1 provides exemplary dimensions of individual facets. The selected leadership parameters refer to the entire leadership model and are related to one or more facets. The controlling influences of a leading unit are divided into measures for controlling the composition of the subordinate units and structuring the social subsystem and measures of institutional, motivational, and informational effects (Novikov, 2007), (Novikov et al., 2010). The first group measures are included in the facet "Working performance" and of the second group in "Employees". The facet "Employees" includes all relations and activities of a manager-leader towards employees: instructions, conflict resolution, support of group performance, permanent team challenge, support of social structure, team composition and development, employee spirit strengthening, employee leadership. These facets border with the facet "Company" at the places of dimensions "culture" and "communication", whereby also "values" could be conceivable. The anthropogenic parameters that describe the facets "Employees" and partly "Company" are work climate, employee loyalty. The facet "Company" refers to enterprise-specific climate, achievement of enterprise goals, living of enterprise culture, own performance of the superior, transmission of enterprise become.

On the other hand, these dimensions are related to "Working performance". The facet "Working performance" includes work methods, control mechanisms, planning and distribution of resources, division of responsibilities. This facet is closely related to all the others, especially "Decision". They share two standard dimensions, "delegation" and "participation" in the sense of decision-making and execution delegation of tasks and areas of responsibility. "Working performance" is related to the facet "Employees" through dimension 
"Decision". The facet "Decision" primarily includes the dimensions of the leadership model around decision context, decision value, decision scope.
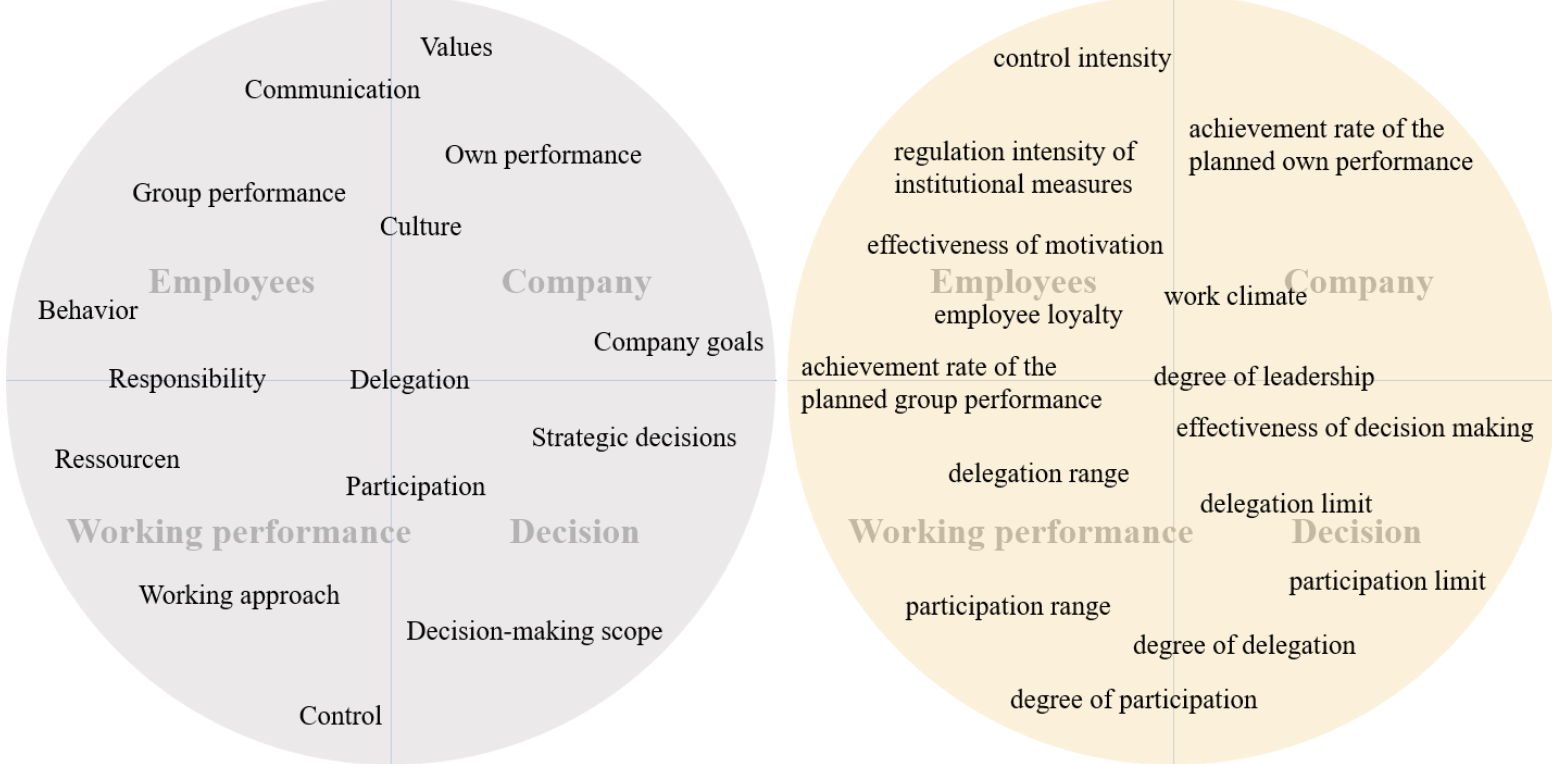

Figure 1. Leadership Facets vs. Leadership Parameters

Source: Compiled by the author

The other parameters are the findings of literature review (the source is declared in parentheses) or selfformulated and are listed:

The span of control is defined as the number of directly subordinated employees. This parameter has a significant impact on the decision-making authority and control since the wrong decision can lead to a greater impact due to the bull-whip effect. The degree of control tends to increase as the number of employees increases (Vahs, 2001).

$>$ Depth of leadership is the number of hierarchy levels. In our case, we refer this term to the leadership unit and count the subordinate hierarchy levels. The degree of control increases from the top management unit through the hierarchy levels (Vahs, 2001).

$>$ The intensity of leadership refers to the ratio between leadership $(\mathrm{Nlu})$ and execution positions $(\mathrm{SpC})$ and is relevant for all the planning and comparison of leadership units (Vahs, 2001).

In our approach, participation refers to the involvement obtained for defined processes on a horizontal lateral relational level. In contrast, we consider delegation as the decision-making responsibilities granted on the part of a superordinate entity and therefore, it refers to the vertical relational level.

The degree of participation is interpreted as the extent of involvement in decision-making, planning, solution and implementation processes (Tannenbaum, \& Schmidt, 1973). Degree of participation is a function of range of participation and is determined by the participation limit. The degree of formalization and personal span determine the participation limit.

$>$ By the delegation degree, we refer to the range of decision-making responsibilities. The delegation degree corresponds to the delegation range, insofar as not all decision-making responsibilities are assigned to the subordinate units over the entire period. Thus, the delegation range is bounded by the delegation limit.

The level of employee loyalty determines the regulation intensity of the institutional impact measures with a certain degree of employee orderliness with a given regulation of activities. Institutional management involves the regulation of behaviour and work practices through the imposition of document-validated constraints and norms. (Azhmukhamedov \& Protalinskiy, 2015).

$>$ Employee loyalty reflects the employee's satisfaction, commitment and motivation levels and describes the willingness to comply with established rules, work regulations and standards of behaviour and is described as a function. Further information about the employee loyalty value calculation can be obtained from (Azhmukhamedov \& Protalinskiy, 2015a).

The work order is used to describe the degree of self-ordering or external order of an organizational subsystem, subordinate to the investigated leadership unit. It is represented as a function and can be calculated according to (Azhmukhamedov \& Protalinskiy, 2015).

$>$ The effectiveness of motivation of subordinate units by the leader is defined as a successful achievement of planned performance. In this case, the performance of all subordinate units is summed up. 
Effectiveness of employees' work is a function of the work activity share in the organizational subsystem in total revenue of the company SheRv and salary for employees from the organizational subsystem Sae and the whole organization Sao (Maksimov, 2006).

Although the work climate parameter is the function of working time and payment, the acknowledgement and the sense of purpose provided by the leader play the most important role.

The achievement rate of the planned group performance denotes the ratio between the target and current performance of a group (team/department/plant) over some time.

The achievement rate of the planned own performance indicates the ratio between target and current performance of a leading unit over some time.

$>$ Effectiveness of decision making is the achievement degree of the set goals. It is represented as a function of input, output, and duration. This parameter can be defined for a decision or a set of decisions or over a measured period of time.

Personality features of a leadership unit are not considered in this model and therefore considered constant.

Formalism. The selected parameters have a mathematical meaning and can be formulated as shown in Table 6:

Table 6. Mathematical Relationships in the Leadership Surrogate Model

\begin{tabular}{|c|c|c|}
\hline Parameter & Formula & № formula \\
\hline Span of control $(S p C)$ & - & \\
\hline Depth of leadership $(\mathrm{DeL})$ & - & \\
\hline Intensity of leadership $(\operatorname{In} L)$ & $\operatorname{InL}=\frac{N l u}{S p C}$ & (1) \\
\hline Degree of participation $(D P)$ & $\begin{array}{l}D P=\left\{\begin{array}{c}0 \\
\operatorname{RaP}\left(\frac{x_{1} \times \text { right }_{1}+x_{2} \times \text { right }_{2}+\cdots+x_{n} \times \text { right }_{n}}{\sum_{1}^{n} \text { right }_{n}}\right) \\
\text { LiP }\end{array}\right. \\
x=\{0<x<1\}\end{array}$ & (2) \\
\hline Degree of delegation $(D D)$ & $\begin{aligned} D D & =\left\{\begin{array}{c}0 \\
\operatorname{RaD}\left(\frac{x_{1} \times \text { right }_{1}+x_{2} \times \text { right }_{2}+\cdots+x_{n} \times \text { right }_{n}}{\sum_{1}^{n} \text { right }_{n}}\right) \\
\text { LiD }\end{array}\right. \\
x=\{0<x<1\} & \end{aligned}$ & (3) \\
\hline Delegation range $(R a D)$ & $R a D=\{0<R a D<L i D\}$ & \\
\hline Delegation limit $(\mathrm{LiD})$ & $L i D=\{0<\operatorname{LiD}<S p C\}$ & \\
\hline Participation range $(R a P)$ & $R a P=\{0<R a P<\operatorname{LiP}\}$ & \\
\hline Participation limit $(\mathrm{LiP})$ & $L i P=\{0<\operatorname{LiP}<D e L\}$ & \\
\hline $\begin{array}{l}\text { Regulation intensity of the institutional } \\
\text { impact measures (RIim) }\end{array}$ & RIim $=f_{E l t} \times f_{W O}$ & (4) \\
\hline Employee loyalty (function) $\left(f_{E l t}\right)$ & $f_{E l t}=\overline{E l t}-\frac{\overline{E l t}}{\left(\overline{E l t}+e^{-a_{E l t}\left(R-b_{E l t}\right)}\right)}$ & (5) \\
\hline Work order (function) $\left(f_{W O}\right)$ & $f_{W O}=\frac{\overline{W O}}{\left(\overline{W O}+e^{-a_{W O}\left(R-b_{W O}\right)}\right)}$ & (6) \\
\hline Effectiveness of motivation $(E M)$ & $\begin{aligned} E M=f(P)= \begin{cases}0, & P c<P t \\
x, & P c \geq P t\end{cases} \\
\\
E M=f_{E l t} \times f_{\text {PSRed }},\left[f_{\text {PSRed }}=\mathrm{const}\right]\end{aligned}$ & (7) \\
\hline Effectiveness of employees' work $(E W)$ & $E W=\frac{\text { SheRv } \times \text { Sae }}{\text { Sao }}$ & (8) \\
\hline Work climate $(W C)$ & - & \\
\hline $\begin{array}{l}\text { Achievement rate of the planned group } \\
\text { performance }(R t G P)\end{array}$ & $R t G P=\frac{P c_{g}}{P t_{g}}$ & (9) \\
\hline $\begin{array}{l}\text { Achievement rate of the planned own } \\
\text { performance }(R t P L)\end{array}$ & $R t P L=\frac{P c_{l}}{P t_{l}}$ & (10) \\
\hline Effectiveness of decision making $(E D M)$ & $E D M=\left(\frac{d_{t}}{d_{c}}\right) \times\left(O_{c}-I\right) \times\left(\frac{O_{c}}{O_{t}}\right)$ & (11) \\
\hline
\end{tabular}

Source: Compiled by the author

In some formula we refer to the following additional parameters:

$P$ - planed performance value;

$P t$ - target performance;

$P t_{g}$ - target performance of a defined antropologycal subsystem of subordinate unit;

$P t_{l}$ - target performance of a leadership unit; 
$P c$ - current performance;

$P c_{g}$ - current performance of a defined antropologycal subsystem of subordinate units;

$P c_{l}$ - current performance of a leadership unit.

We analyzed scientific findings on the description and measurement of defined features and obtained the following correlations:

$$
D L=\left\{\begin{array}{c}
I n L \\
D D \\
D P \\
E M \\
P \\
W C \\
E W \\
E D M
\end{array}\right.
$$

The degree of leadership varies depending on the value of the respective parameters. The relevant KPIs of a company can also be included in this model.

Obtaining the exact surrogate model based on dataset. The proposed surrogate model is a mathematical framework that can be used for elaborated scenarios. This model is particularly applicable for combined leadership styles or novelty leadership approaches. The data obtained so far, and correlations drawn can be used for individual scenarios.

\section{Conclusions}

The model we have developed offers the possibility of implementation in the digital organizational system with minimal adaptation and post-processing. Although the model specifies only selected parameters, it covers a relatively wide range of characteristics describing leadership since many even undesignated parameters are in direct correlation with each other. The surrogate model can be used to identify individual leadership styles or to identify leadership development opportunities. Some surrogate model parameters can be formulated in various ways. We offer an integrative variant. It can be adapted for your purposes and enhanced by other parameters. Improvements to the proposed model include implementing personal characteristics, numerous intra-organizational parameters, relationships with single superior and subordinate units, etc. Researchers and practitioners can use the surrogate model we have developed for different purposes in building a digital organization system. By additional implementation of datasets, different scenarios can be simulated based on our model and thus, further situation-based substitute models can be generated.

Funding. The originality of our research resides in the synthesis of a new surrogate leadership model. The findings can be used for the digital replication of the Leadership unit, and as a distinct mathematical model.

\section{References}

1. Acharya, G. (2010). A Mathematical Model of Organisational Leadership. SSRN, 10. 12. 2010. 1-14. DOI:10.2139/ssrn.1909385.

2. Adair, J., \& Adair, J. E. (1988). The Action Centred Leader. Industrial Society (2nd ed.).

3. Azhmukhamedov, A. I., \& Protalinskiy, O. M. (2015 a). Evaluating the efficiency of motivation in human resource management. Vestnik SGTU, 3(80), 107-114. Available at: https://cyberleninka.ru/article/n/otsenka-effektivnosti-motivatsionnyh-komponent-v-upravleniitrudovympovedeniem-rabotnikov-transnatsionalnoy-korporatsii.

4. Azhmukhamedov, A. I., \& Protalinskiy, O. M. (2015 b). Mathematical model the efficiency of the staff depending on the intensity institutional interventions. Uprawlenie $w$ sozial'nych i ekonomitscheskich sistemach, 4, 110-117. Available at: https://cyberleninka.ru/article/n/matematicheskayamodeleffektivnosti-raboty-personala-v-zavisimosti-ot-intensivnosti-institutsionalnyh-mer-vozdeystviya.

5. Hersey, P., \& Blanchard, K. (1988). Management and organizational behavior: Utilizing human resources (5th ed.). Englewood Cliffs, NJ: Prentice-Hall. 169-201. Available at: https://ess220.files.wordpress.com/2008/02/hersey-blanchard-1988.pdf.

6. Kouzes, J., \& Posner, B. (2012). The Leadership Challenges: How to Make Extraordinary Things Happen in Organizations. San Francisco, CA: The Leadership Challenge - A Willy Brand. Available at: https://edisciplinas.usp.br/pluginfile.php/3988308/mod_resource/content/2/LEADERSHIP\%20CHALLE NGE.pdf. 
7. Maksimov, A.A. (2006). Mathematical model of the mechanism of promotion of enterprise employees. Vestnik $O G U, 2(2), 144-147$. Available at: https://cyberleninka.ru/article/n/matematicheskaya-modelmehanizma-stimulirovaniya-rabotnikov-predpriyatiya.

8. Mejia, J. S., Mejia, S. E., Ramirez, C. M. Z. (2009). Mathematical Model of Leadership for organizational leaders. Scientia et Technica Año 15(43), 106-111. Available at: http://www.utp.edu.co/php/revistas/ScientiaEtTechnica/docsFTP/74927106-111.pdf.

9. Moradinasab, N., Soofifard, R., Asili, G.R. (2016). Developing an effective mathematical model for leadership styles selection by using fuzzy logic: a case on RIPI HR characteristics. International Journal of Productivity and Quality Management (IJPQM), 19(4), 466-484. DOI:10.1504/IJPQM.2016.080153.

10. Novikov, D.A. (2007). Teoriia upravleniia organizatsionnymi sistemami [Theory of control of the organizational systems]. Moscow, Fizmatlit Publ. 584 p. Available at: http://www.aup.ru/books/m1379/.

11. Novikov, D.A., Gubanov, D.A., Chkhartishvili, A.G. (2010). Sotsial'nye seti: modeli informatsionnogo vliianiia, upravleniia i protivoborstva [Social networks: models of information influence, control and collision]. Moscow, Fizmatlit Publ. 228 p. Available at: https://b-ok.cc/book/779797/d0d3c2.

12. Skrynnyk, O., \& Vasilyeva, T. (2020). Neuro-Genetic Hybrid System for Management of Organizational Development Measures. CEUR Workshop Proceedings 2732, 411-422. Available at: https://www.scopus.com/record/display.uri?eid=2-s2.0-85096109482\&origin=resultslist\&sort=plf-

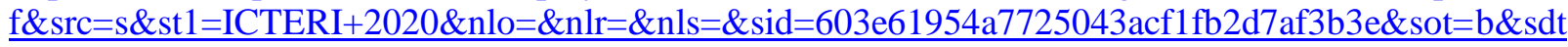
$=$ sisr \&sl=17\&s=CONF\% 28ICTERI+2020\%29\&ref $=\% 28 \% 280 l e n a \% 2 c+S . \% 29 \% 29+A N D+\% 280 l e n a$ $\% 2 \mathrm{c}+\mathrm{S} . \% 2 \mathrm{c}+$ Tetyana\%2c+V.\%29\&relpos $=0 \& \mathrm{citeCnt}=0 \&$ searchTerm $=$ Volume $: 2732$.

13. Stogdill, R.M. (1948). Personal Factors Associated with Leadership: A Survey of the Literature. The Journal of Psychology, 25, 35-71. DOI:10.1080/00223980.1948.9917362.

14. Tannenbaum, R., \& Schmidt, W.H. (1958). How to choose a leadership pattern. Harvard Business Review 36(2), 95-101. DOI:10.4324/9781315250601-8.

15. Tannenbaum, R., \& Schmidt, W.H. (1973). How to Choose a Leadership Patterns. Harvard Business Review, 51, 162-180. Available at: https://hbr.org/1973/05/how-to-choose-a-leadership-pattern.

16. Vahs, D. (2001). Organisation: Einführung in die Organisationstheorie und -praxis. [Organization: introduction to organizational theory and practice] Praxisnahes Wirtschaftsstudium (3rd ed.). SchäfferPoeschel, 95-100. 